\title{
Health layering of self-help groups: impacts on reproductive, maternal, newborn and child health and nutrition in Bihar, India
}

Kala M Mehta ${ }^{1,2}$, Laili Irani ${ }^{3}$, Indrajit Chaudhuri ${ }^{4}$, Tanmay Mahapatra ${ }^{5}$, Janine Schooley ${ }^{4}$, Sridhar Srikantiah ${ }^{5}$, Safa Abdalla', Victoria C Ward ${ }^{1}$, Suzan L Carmichael $^{1,6}$, Jason Bentley ${ }^{7}$, Andreea Creanga $^{8}$, Jess Wilhelm ${ }^{8}$, Usha Kiran Tarigopula ${ }^{9}$, Debarshi Bhattacharya ${ }^{9}$, Yamini Atmavilas ${ }^{9}$, Priya Nanda ${ }^{9}$, Yingjie Weng ${ }^{7}$, Kevin T Pepper ${ }^{1}$, Gary L Darmstadt ${ }^{1,6}$; for the Ananya Study Group

\footnotetext{
${ }^{1}$ Department of Pediatrics, Stanford University School of Medicine, Stanford, California, USA

${ }^{2}$ Department of Epidemiology and Biostatistics, University of California San Francisco, San Francisco, California, USA

${ }^{3}$ Population Council, New Delhi, India

${ }^{4}$ Project Concern International, Delhi, India and San Diego, California, USA

${ }^{5}$ CARE India, Patna, India

${ }^{6}$ Center for Population Health Sciences, Stanford

University School of Medicine, Palo Alto,

California, USA

${ }^{7}$ Quantitative Sciences Unit, Department of Medicine, Stanford University School of Medicine, Stanford, California, USA

${ }^{8}$ Department of International Health, Johns Hopkins Bloomberg School of Public Health, Baltimore, Maryland, USA

${ }^{9}$ Bill and Melinda Gates Foundation, Delhi, India
}

\section{Correspondence to:}

Gary L. Darmstadt, MD

Department of Pediatrics

Stanford University School of Medicine

1701 Page Mill Road

Palo Alto, CA 94304

USA

gdarmsta@stanford.edu

\begin{abstract}
Background Self-help group (SHG) interventions have been widely studied in low and middle income countries. However, there is little data on specific impacts of health layering, or adding health modules education upon existing SHGs which were formed primarily for economic empowerment. We examined three SHG interventions from 2012-2017 in Bihar, India to test the hypothesis that health-layering of SHGs would lead to improved health-related behaviours of women in SHGs.
\end{abstract}

Methods A model for health layering of SHGs - Parivartan - was developed by the non-governmental organisation (NGO), Project Concern International, in 64 blocks of eight districts. Layering included health modules, community events and review mechanisms. The health layering model was adapted for use with government-led SHGs, called JEEViKA+HL, in 37 other blocks of Bihar. Scale-up of government-led SHGs without health layering (JEEViKA) occurred contemporaneously in 433 other blocks, providing a natural comparison group. Using Community-based Household Surveys (CHS, rounds 6-9) by CARE India, 62 reproductive, maternal, newborn and child health and nutrition (RMNCHN) and sanitation indicators were examined for SHGs with health layering (Pavivartan SHGs and JEEViKA+HL SHGs) compared to those without. We calculated mean, standard deviation and odds ratios of indicators using surveymeans and survey logistic regression.

Results In 2014, 64\% of indicators were significantly higher in Parivartan members compared to non-members residing in the same blocks. During scale up, from 2015-17, half (50\%) of indicators had significantly higher odds in health layered SHG members (Parivartan or JEEViKA+HL) in 101 blocks compared to SHG members without health layering (JEEViKA) in 433 blocks.

Conclusions Health layering of SHGs was demonstrated by an NGO-led model (Parivartan), adapted and scaled up by a government model (JEEViKA+HL), and associated with significant improvements in health compared to non-health-layered SHGs (JEEViKA). These results strengthen the evidence base for further layering of health onto the SHG platform for scale-level health change.

Study registration ClinicalTrials.gov number NCT02726230 
Few interventions reach across the Sustainable Development Goals (SDGs) goals with the potential to address several SDGs simultaneously [1]. Self-help groups (SHGs) are a notable exception. In these groups, also known as women's empowerment collectives and by a myriad of other names, women come together in groups of 10-20 for mutual aid and benefit. Groups are often formed for purposes of gaining access to credit or promoting livelihoods [2]. The women who participate in SHGs are typically low-income, mostly rural, and historically lack agency surrounding their own financial or health concerns [3]. By coming together for a common purpose, women in these groups, as Amartya Sen put it, counter the 'feminisation of poverty' [4]. SHGs often selectively engage the most marginalised communities, and thus have the potential to also improve equity $[5,6]$. Because of the varied form and structure of SHGs, their importance may extend well beyond purely financial and livelihood outcomes, leading to changes in health-related behaviours, shifting social norms and improving a wide range of health-related outcomes.

In India, SHGs started over 30 years ago with a direct tie to microfinance. SHGs have since expanded throughout India, including an estimated 200 million members in nine million SHGs; most maintain a goal of economic empowerment [7]. In 2006, the Bihar Rural Livelihood Program (BRLP) model locally known as 'JEEViKA,' which means 'livelihood' in Hindi - was launched. JEEViKA is a government-run program largely funded by the World Bank that supports the formation and nurturing of SHGs based on microfinance and livelihoods promotion [8]. We call this SHG model "JEEViKA," which did not have an explicit health component at the beginning of our evaluation in 2012.

In 2011, the Bill and Melinda Gates Foundation (BMGF) funded the Parivartan ("Transformation" in Hindi) project, which was implemented starting in 2012 by the non-governmental organisation (NGO) Project Concern International (PCI). Parivartan engaged women as change agents at family and community levels with the strategic objective of influencing health, nutrition and sanitation knowledge, practices and behaviours among women of reproductive age from the most marginalised communities in the eight focus districts (comprised of 64 blocks) of BMGF's Ananya pilot program in Bihar (Figure 1). The SHG intervention complemented supply side support to the Government of Bihar (GoB) provided by CARE India and the social and behaviour change communications (SBCC) of BBC Media Action. Parivartan was a pilot project to understand processes and benefits of layering health interventions - namely reproductive, maternal, newborn and child health and nutrition (RMNCHN) and sanitation interventions - onto the SHG platform which historically had been formed based on microfinance and livelihood interventions. Parivartan was phased out in 2015; however, the SHGs created through Parivartan were transitioned to the government-run JEEViKA program and health layering was expanded. Evaluation by Population Council showed encouraging results across most RMNCHN indicators for Parivartan [9].

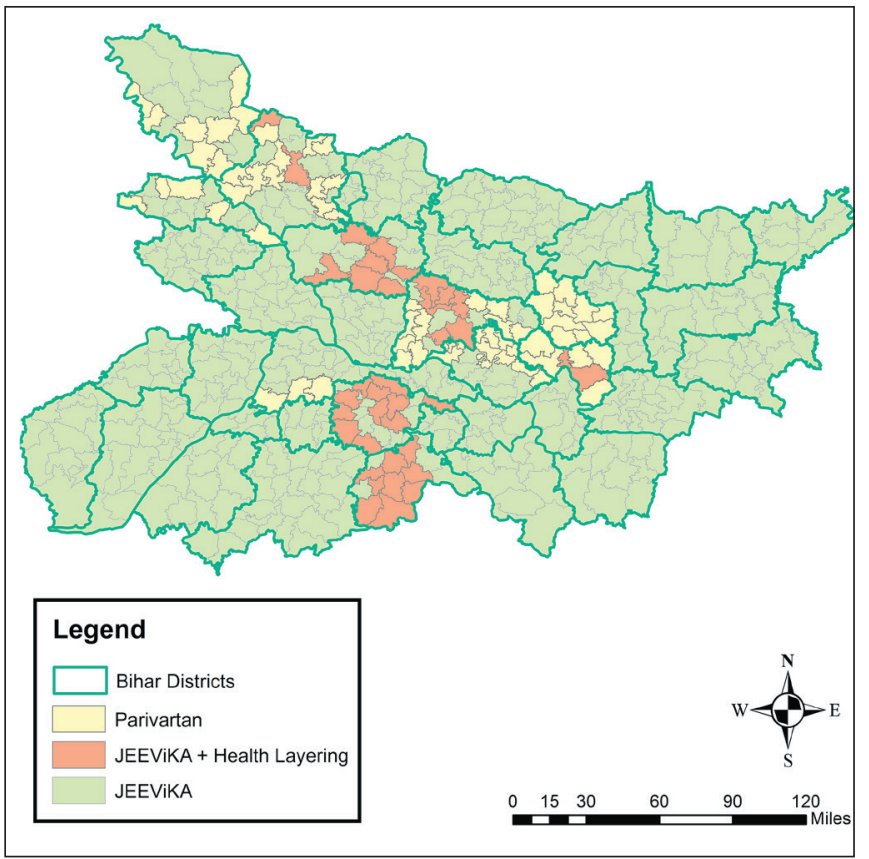

Figure 1. Map of Bihar showing self-help group types, 2014-2017.
To test the feasibility of implementing interventions similar to the NGO-led Parivartan model, but adapted for implemention among government-led JEEViKA SHGs, health layering was extended by PCI to 9089 JEEViKA SHGs in 37 additional blocks. Successful health layering of interventions in JEEViKA SHGs, creating JEEViKA+HL SHGs enhanced the interest of the GoB in scaling-up and leveraging community platforms to move the state's health agenda forward. At the request of JEEViKA and the World Bank, PCI conceptualised the JEEViKA Technical Support Program (JTSP) in 2015 with the objective of providing support to the government to further scale up health layering in JEEViKA SHGs (Figure 2).

Despite increased global interest in health-layered SHG models, few evaluations have examined the health impacts of these interventions in relation to comparable, non-health-layered SHGs. Published reports poorly define health-layering and/or show mixed effects of health layering on a variety of health outcomes, such as maternal and child health, nutrition, gender violence, and mental health; in general, reports are lacking in aspects 


\begin{tabular}{|c|c|c|c|c|}
\hline 2012 & 2014 & 2015 & 2017 & 2018 \\
\hline $\begin{array}{l}\text { Testing } \\
\text { efficacy }\end{array}$ & $\begin{array}{l}\text { Program } \\
\text { effectiveness }\end{array}$ & $\begin{array}{l}\text { Layering } \\
\text { phase }\end{array}$ & $\begin{array}{l}\text { Integ } \\
\text { phase }\end{array}$ & \\
\hline $\begin{array}{l}\text { NGO-led } \\
\text { Parivartan } \\
\text { Health layering } \\
\text { Districts: } 8 \\
\text { Blocks: } 55 \\
\text { Villages: } 2,064 \\
\text { Groups: } 17,214 \\
\text { Women: } 250,000 \\
\text { Funding SHG: BMGF } \\
\text { Funding HL: BMGF }\end{array}$ & $\begin{array}{l}\text { Government-led } \\
\text { Testing health } \\
\text { integration } \\
\text { Groups: } 9000 \\
\text { Funding SHG-Gov } \\
\text { Funding HL-BMGF }\end{array}$ & $\begin{array}{l}\text { JEEViKA Technical } \\
\text { Support program } \\
\text { Districts:11 } \\
\text { Blocks:101 } \\
\text { Funding SHG \& health } \\
\text { intervention-Gov } \\
\text { BMGF/PCI HR support at } \\
\text { district and block level, } \\
\text { capacity building and } \\
\text { technical support }\end{array}$ & $\begin{array}{l}\text { Scale ur } \\
\text { Districts } \\
\text { Blocks: } \\
\text { Villages } \\
\text { Groups: } \\
\text { Women } \\
\text { SHG/HL } \\
\text { BMGF/ } \\
\text { quality } \\
\text { handho } \\
\text { Overall }\end{array}$ & $\begin{array}{l}\text { on } \\
\text { ment } \\
\text { :ity building, } \\
\text { ent, and } \\
\text { poort } \\
\text { I support }\end{array}$ \\
\hline
\end{tabular}

Figure 2. Timeline of Health Layering of Self-help Groups in Bihar, 2012-2018 of quality in study design or a comparison group of SHG non-members [10-19].

The current study aims to address this evidence gap, building on preliminary promising results of the Parivartan intervention and capitalising on a natural comparison group, ie, non-health-layered JEEViKA SHGs $[9,17,20]$. Our analyses examine the impact of the NGO-led Parivartan model of health layering of SHGs, the impact of health-layering adapted for government-led SHGs during scale-up, and the isolated contribution of health layering by comparison with SHGs formed for purposes of microfinance and livelihoods promotion. We hypothesised that health-layered SHGs would have better performance on a broad range of RMNCHN indicators compared to non-health-layered SHGs.

\section{METHODS}

\section{SHG Interventions}

\section{Health-layering of SHGs in the context of the Ananya program at scale}

In order to examine the added effects of health layering on SHGs formed for promotion of livelihoods and access to credit, the strongest design would be a cluster randomised controlled trial comparing SHGs with or without health layering. A trial design was not feasible. Instead, we used a 'natural' separation of the groups with and without health layering in specific geographic blocks of Bihar, India and used these separations for an observational comparison.

SHG health-layered interventions were undertaken as part of a comprehensive suite of interventions funded by the BMGF in partnership with the GoB, as described previously [21,22]. The primary goal of the Ananya program was to strengthen the capacity of the GoB to improve RMNCHN outcomes statewide. Several NGOs, including CARE India [23-28], BBC Media Action [29] and PCI [30] launched or supported the government in implementing a range of RMNCHN interventions during the Ananya pilot period of 2012 through 2013 in eight focus districts: Patna, Saharsa, East Champaran, West Champaran, Samastipur, Bengusarai, Gopalganj and Khagaria. During this pilot phase, PCI developed the Parivartan NGO-led health-layered SHG intervention in these eight districts ( 64 blocks). The Parivartan project officially started in November 2011 and implementation began in early 2012. In 2015, Parivartan groups were phased out and SHGs were scaled-up by the GoB statewide across all 38 districts. During scale-up, BMGF funded PCI to apply learning from Parivartan and provide technical support through the JEEViKA Technical Support Program (JTSP) to health layering of government-led SHGs in the 64 blocks of the eight focus districts. The JTSP also helped to promote health layering of former and newly formed JEEViKA groups in 37 additional blocks in three additional districts (Figure 1). Overall, by 2015 there were health-layered SHGs in 101 blocks of Bihar, while government-led JEEViKA SHGs without health layering were scaled up across the rest of the 433 blocks in the state.

\section{Parivartan NGO-led health-layered SHGs: demonstration of the model}

Parivartan formed new SHGs in marginalised communities comprised exclusively of Scheduled Tribes or Scheduled Castes (Hindu) or Pashmunda Muslims; some SHGs integrated Scheduled Tribes and Scheduled Castes together. Parivartan facilitated mutual learning and collective action, including Participatory Learning and Action (PLA), social mobilisation and empowerment, SBCC interventions and health education modules layered onto SHGs newly formed for microfinance and livelihoods promotion. Eleven health modules were layered upon NGO-led SHGs covering antenatal care, birth preparedness, postpartum and postnatal care, exclusive breastfeeding, complementary feeding, immunisations and sanitation behaviours (Table 1). Thus, "health layering" included promotion of health, nutrition and santitation behaviours across the RMNCHN continuum of care. Women were taught key health messages; empowered to develop confidence, self-esteem, and self-agency as well as social cohesion and collective action; and enabled to advocate for improvements in the quality of health services and to influence key health, nutrition and sanitation behaviours 
in their households and communities [9,20,31,32]. Sahelis ("female friends" in Hindi) were village-based volunteers who were trained to_facilitate the adoption of improved behaviours through weekly educational and game-based sessions, and complementary activities such as accompanying women to antenatal and postnatal care visits. Sahelis were often younger women from similar communities with an expressed interest in health and had vocational training but not formal training in health and were supervised by officials as part of a tiered SHG structure called the Village Organisation. The intervention emphasised a linkage to existing village-level organisations and activities such as the Village Health, Sanitation and Nutrition Days (VHSNDs) and the work of CARE India and BBC Media Action to strengthen the subcentre health platform and the work of frontline workers (FLWs) [ie, Accredited Social Health Activists (ASHAs), Anganwadi Workers (AWWs), and Auxilliary Nurse Midwives (ANMs)] [23-26]. The Parivartan model for health layering upon NGO-led SHGs was developed in approximately 18000 newly formed SHGs from 2012-2014 in 64 blocks during the eight-district pilot phase of Ananya, as described previously [21,22].

Table 1. Interventions in Parivartan health layering*

\begin{tabular}{|c|c|c|c|}
\hline SEssion & INTERVENTION CONTENT FOCUS & ANTicipated leARMING OF SELF-HELP Groups (SHGS) & MODE OF DELIVERY \\
\hline \multirow[t]{2}{*}{1} & \multirow[t]{2}{*}{ Introductory module } & \multirow[t]{2}{*}{ Interrelation between health and livelihood } & $\begin{array}{l}\text { Banner with key messages and story of two women who } \\
\text { had to invest a loan amount on a health emergency }\end{array}$ \\
\hline & & & $\begin{array}{l}\text { Consent letter by the SHG to continue the discussion on } \\
\text { health, nutrition and sanitation }\end{array}$ \\
\hline \multirow[t]{3}{*}{2} & \multirow{3}{*}{$\begin{array}{l}\text { Antenatal care (ANC) and } \\
\text { birth preparedness }\end{array}$} & Early registration for ANC & \multirow{3}{*}{ Message card and story of a Musahar pregnant lady } \\
\hline & & Receipt of iron-folic acid tablets & \\
\hline & & Delivery in an institution & \\
\hline \multirow[t]{4}{*}{3} & \multirow{4}{*}{$\begin{array}{l}\text { Postnatal care. Focus of this } \\
\text { module on early breastfeeding } \\
\text { and neonatal behaviors like } \\
\text { delayed bath, skin-to-skin care } \\
\text { and dry cord care }\end{array}$} & Early initiation of breast feeding & \multirow[t]{4}{*}{ Story of a lady named Sarita who has just delivered } \\
\hline & & Not applying anything to the cord & \\
\hline & & Delaying bath for at least 72 hours & \\
\hline & & Practice skin-to-skin care & \\
\hline \multirow[t]{2}{*}{4} & \multirow{2}{*}{$\begin{array}{l}\text { Exclusive breastfeeding and } \\
\text { supplementary nutrition }\end{array}$} & Exclusive breastfeeding for at least 6 months & \multirow[t]{2}{*}{ Message card and picture puzzle card } \\
\hline & & $\begin{array}{l}\text { Children above } 6 \text { months given cereal based } \\
\text { semi-solid food }\end{array}$ & \\
\hline \multirow[t]{2}{*}{5} & \multirow[t]{2}{*}{ Routine immunization } & $\begin{array}{l}\text { Children receive appropriate doses of } \\
\text { intervention according to schedule }\end{array}$ & \multirow[t]{2}{*}{$\begin{array}{l}\text { Banner with key messages and song, a Sohar, a song which } \\
\text { is traditionally Bihari and sung at the birth of a child }\end{array}$} \\
\hline & & Children complete DPT-3 & \\
\hline \multirow[t]{2}{*}{6} & \multirow[t]{2}{*}{ Family planning } & Women use postpartum contraception & \multirow[t]{2}{*}{ Story card with pictures } \\
\hline & & $\begin{array}{l}\text { Women continue to use contraception to } \\
\text { prevent unintended pregnancies }\end{array}$ & \\
\hline \multirow[t]{3}{*}{7} & \multirow{3}{*}{$\begin{array}{l}\text { Personal hygiene and safe } \\
\text { storage of water for the } \\
\text { household }\end{array}$} & Decrease water borne disease & \multirow[t]{3}{*}{ Picture cards and song } \\
\hline & & Safe storage of water at household level & \\
\hline & & Handwashing at critical times & \\
\hline \multirow[t]{2}{*}{8} & \multirow[t]{2}{*}{$\begin{array}{l}\text { Use of toilet and garbage } \\
\text { management }\end{array}$} & Use of toilet & $\begin{array}{l}\text { Faeces mapping(places used for open defacation were } \\
\text { marked in yellow and then visualized so that community } \\
\text { members could see all places at risk for contamination. }\end{array}$ \\
\hline & & Safe disposal of child's stool & Picture card and song \\
\hline
\end{tabular}

DPT - diphtheria-pertussis-tetanus

*Adapted with permission from Saggurti et al., 2018 [9].

\section{Layering of health into JEEViKA (JEEViKA+HL) SHGs for scaling}

During the scale-up phase of Ananya beginning in 2014, the Parivartan intervention was phased-over to JEEViKA, with technical support from the JTSP and funding from the World Bank and the GoB. JEEViKA assumed the management of health-layered SHGs formed under Parivartan, and operationalised a tiered system of GoB-led SHGs starting with community mobilisation for women, then arranging them into SHGs, which were in turn aggregated into Village-level Organisations. These were further aggregated to clusters of federations at sub-block level [30]. Additional groups were scaled-up in the original 64 Parivartan blocks through the formation of new health-layered JEEViKA+HL SHGs. In an additional 37 blocks, capacity building of groups originally formed under JEEViKA to promote microfinance and livelihoods was also undertaken to layer in health, nutrition and sanitation programming under the JTSP. Thus, by 2015 a total of 101 out of 534 blocks in Bihar had approximately 150000 health-layered SHGs [33]. The role of the Sahelis was replaced by JEEVIKA's own grassroots cadre of community mobilisers who were trained on RMNCHN and sanitation messages by PCI. 


\section{Non-health-layered JEEViKA SHGs at scale}

Non-health-layered JEEViKA SHGs in 433 other blocks throughout Bihar - separate from the 101 blocks where health layering of SHGs occurred - used the same tiered JEEViKA organisational structure and had an explicit credit and livelihood or agricultural focus, but did not include specific health, nutrition or sanitation interventions in 2016. The types of groups and their spread and scale-up can be viewed on the World Bank portal: https://arcg.is/051m4X.

\section{Evaluation}

\section{Community-based Household Surveys}

To monitor progress of implementation of the Ananya program, CARE India undertook a series of Community-based Household Surveys (CHS) using a Lot Quality Assurance Sampling (LQAS)-like methodology, as described previously $[23,34]$. In the context of SHGs, the CHS surveys can be viewed as an independent data source as data were collected by CARE India's Concurrent Measuring and Learning unit which was functionally independent of implementation. Questions to women in these surveys regarding their participation in SHGs started in survey round 6 in 2014 and continued through round 9 in 2017. In rounds 6-9 of the CHS, the methodology of survey administration and calculation of survey weights followed LQAS+ methodology in all 38 districts as described previously [23,34]. Within districts, the sampling frame was constructed within blocks from area Anganwadi Centers (AWCs) which are village-level institutions that provide basic education and nutrition services. From each selected AWC catchment area, eligible households were defined as containing a mother with a live birth and a young child in one of five age groups (0-2, 3-5, 6-8, 9-11 and 12-23 months). For each block, the sample size was proportionate to the known population of the block, subject to a minimum of 19 households. Women whose children had died in early childhood were not included. Data collection teams from CARE India went to each randomly selected household and administred surveys specific for mothers who had a child in one of five age groups to enable assessment of age-specific indicators across multiple domains of the continuum of care for health, nutrition and sanitation. This provided a sample size of 15687 , across all districts of the state, for each of the five age groups, for each CHS survey.

CHS survey questions about particiption in SHGs were utilised to identify women who self-identified as being a member of an SHG. To define the type of SHG to which women belonged, information available on the of implementation of SHGs in specific blocks in Bihar was used. The Parivartan program was implemented in 64 blocks in the eight original focus districts of Ananya; at that time the governmental JEEViKA program was not yet active in these blocks. Thus, if a woman surveyed at the time of CHS round 6 (mid-2014) said she was a member of a SHG and lived in one of these 64 blocks, we assigned her to the SHG type Parivartan. Age-comparable women residing in the same blocks but who did not report membership in an SHG served as the comparison group for assessment of impacts of Parivartan health-layered SHGs. During round 6 in 2014, no health layering of SHGs was occurring in the other 469 blocks in Bihar.

At the time of CHS rounds 8 and 9 (2016-2017), groups in the former Parivartan health layered blocks ( $n=64)$ had been transitioned to the government to manage or were newly formed government-managed groups into which health layering had occurred; we identified both of these types of groups as JEEViKA+HL. Also in rounds 8 and 9, 37 additional blocks engaged in health layering upon existing government groups; women in those blocks who self-identified as SHG members at that time were defined as belonging to JEEViKA+HL groups. Although they had different origins, the health-layered groups in all 101 blocks shared a common JEEViKA management structure in rounds 8 and 9. The rest of the blocks of the state $(n=433)$ were considered non-health-layered JEEViKA groups, as regular SHGs without specific health layering were predominant throughout the rest of the state during this time period.

Using this information, we were able to separate women into three types of SHGs: 1) Health-layered NGO-led Parivartan SHGs funded by the BMGF and led by PCI in 64 blocks from 2011-2014 (assessed in CHS round 6); 2) Health-layered JEEViKA+HL groups coming from two sources: a) the original 64 Parivartan blocks where health-layered Parivartan SHGs transitioned in 2014-2015 to JEEViKA+HL SHGs which were managed under the JTSP, and b) 37 additional blocks where health was layered into JEEViKA SHGs, for a total of 101 blocks with JTSP-managed JEEViKA+HL SHGs in 2015-2017 (assessed in CHS rounds 8-9 in 2016-2017); and 3) Non-health-layered JEEViKA SHGs in the state's remaining 433 blocks in 2015-2017 (assessed in CHS rounds 8-9 in 2016-2017). 


\section{Indicator selection and categorisation}

We focused on 62 indicators which broadly reflected the original health, nutrition and sanitation modules developed for Parivartan SHGs and adapted for scale-up through JEEViKA+HL SHGs (Table 2). We restricted our analytical cohort to women with children aged 0-2 months for antenatal, delivery, postnatal newborn and postpartum family planning indicators; 9-11 months for immunisation and complementary feeding indicators, and 12-23 months for family planning and sanitation. These indicators were selected because they were most relevant to the health modules layered upon SHGs and represented a broad array of indicators across the RMNCHN continuum of care and delivery platforms.

Table 2. Reproductive, maternal, newborn and child health, nutrition and sanitation indicators by continuum of care domain and delivery platform from Community-based Household Surveys

\begin{tabular}{|c|c|c|c|c|c|}
\hline & InDicatoR & $\begin{array}{l}\text { CONTINUUM OF CARE } \\
\text { DOMAIN }\end{array}$ & DeLUVERY PLATFORM & VABiable naME & $\begin{array}{l}\text { AGE } \\
\text { GROUP }\end{array}$ \\
\hline 1 & 4+ ANC visits & Antenatal care & Facility/outreach service delivery & r_fouranc & $0-2$ \\
\hline 2 & Had at least one ANC exam if reporting any ANC visit & Antenatal care & Facility/outreach service delivery & Anyancexam & $0-2$ \\
\hline 3 & Admitted to hospital for complication & Antenatal care & Facility/outreach service delivery & admitcompl & $0-2$ \\
\hline 4 & Received at least 90 IFA tablets during pregnancy & Antenatal care & Facility/outreach service delivery & gotifa90 & $0-2$ \\
\hline 5 & FLW antenatal home visit to discuss mother's or baby's health & Antenatal care & Frontline worker performance & flwvishlth & $0-2$ \\
\hline 6 & Any FLW visit during last trimester & Antenatal care & Frontline worker performance & any_flw_3rdtrim & $0-2$ \\
\hline 7 & FLW advised on hand-washing by delivery attendant & Antenatal care & Frontline worker performance & advice_hand & $0-2$ \\
\hline 8 & FLW advised on danger of excessive bleeding & Antenatal care & Frontline worker performance & advice_bleed & $0-2$ \\
\hline 9 & FLW advised on danger of convulsions & Antenatal care & Frontline worker performance & advice_conv & $0-2$ \\
\hline 10 & FLW advised on danger of prolonged or difficult labor & Antenatal care & Frontline worker performance & advice_labor & $0-2$ \\
\hline 11 & FLW advised on danger of swelling of face or hands & Antenatal care & Frontline worker performance & advice_edema & $0-2$ \\
\hline 12 & FLW advised on reasons to deliver in a hospital & Antenatal care & Frontline worker performance & advice_facdel & $0-2$ \\
\hline 13 & FLW advised on saving money in case of emergency & Antenatal care & Frontline worker performance & advice_money & $0-2$ \\
\hline 14 & FLW advised on pregnancy danger signs & Antenatal care & Frontline worker performance & advice_preg_signs & $0-2$ \\
\hline 15 & Consumed 90+ IFA tablets & Antenatal care & Mother's behaviour & tookifa90 & $0-2$ \\
\hline 16 & Pregnancy registration in the first trimester & Antenatal care & Mother's behaviour & pregreglsttrim & $0-2$ \\
\hline 17 & Sought care for complications & Antenatal care & Mother's behaviour & r_careseeking_compl & $0-2$ \\
\hline 18 & Saved money & Antenatal care & Mother's behaviour & savemoney & $0-2$ \\
\hline 19 & Chose a facility for delivery & Antenatal care & Mother's behaviour & pickfac & $0-2$ \\
\hline 20 & Chose a facility in case of emergency & Antenatal care & Mother's behaviour & pickemfac & $0-2$ \\
\hline 21 & Arranged transportation to facility & Antenatal care & Mother's behaviour & pickvehicle & $0-2$ \\
\hline 22 & Delivery in a facility (public or private) & Delivery & Facility/outreach service delivery & pod_facility & $0-2$ \\
\hline 23 & Delivery in a private facility (out of all deliveries) & Delivery & Facility/outreach service delivery & privatefac & $0-2$ \\
\hline 24 & Delivery in a public facility (out of all deliveries) & Delivery & Facility/outreach service delivery & publicfacoffac2 & \\
\hline 25 & Caesarian-section for delivery & Delivery & Facility/outreach service delivery & Csection & $0-2$ \\
\hline 26 & New blade was used to cut cord & Delivery & Facility/outreach service delivery & new_blade & $0-2$ \\
\hline 27 & Clean cloth was used for baby & Delivery & Facility/outreach service delivery & clean_cloth & $0-2$ \\
\hline 28 & Clean thread was used to tie cord & Delivery & Facility/outreach service delivery & clean_thread & $0-2$ \\
\hline 29 & Baby weighed at birth & Delivery & Facility/outreach service delivery & r_weighed & $0-2$ \\
\hline 30 & Baby immediately dried and wrapped & Delivery & Mother's behaviour & dried_wrapped & $0-2$ \\
\hline 31 & Any FLW visits in the first week after delivery & Postnatal care & Frontline worker performance & any_flw_visit_lstweek & $0-2$ \\
\hline 32 & $3+$ FLW visits in the first week after delivery & Postnatal care & Frontline worker performance & $\begin{array}{l}\text { three_flw_ } \\
\text { visit_lstweek }\end{array}$ & $0-2$ \\
\hline 33 & FLW advised on neonatal danger signs & Postnatal care & Frontline worker performance & advice_neonatal_signs & $0-2$ \\
\hline 34 & FLW advised on delayed bathing & Postnatal care & Frontline worker performance & advice_delaybath & $0-2$ \\
\hline 35 & FLW advised on skin-to-skin care & Postnatal care & Frontline worker performance & advice_stsc_new & $0-2$ \\
\hline 36 & FLW advised on dry cord care & Postnatal care & Frontline worker performance & advice_dry_cord & $0-2$ \\
\hline 37 & Skin-to-skin care & Postnatal care & Mother's behaviour & stsc_imm_later & $0-2$ \\
\hline 38 & Dry cord care & Postnatal care & Mother's behaviour & drycordcare3 & $0-2$ \\
\hline 39 & Delayed bath & Postnatal care & Mother's behaviour & delay_bath & $0-2$ \\
\hline 40 & Care seeking for neonatal complications & Postnatal care & Mother's behaviour & $\begin{array}{l}\text { r_careseeking } \\
\text { newborn }\end{array}$ & $0-2$ \\
\hline 41 & FLW advised on early initiation of breastfeeding & Nutrition & Frontline worker performance & advice_bf_pre & $0-2$ \\
\hline 42 & FLW advised on exclusive breastfeeding & Nutrition & Frontline worker performance & advice_exc_bf & $0-2$ \\
\hline 43 & FLW advised on age to which to continuing breastfeeding & Nutrition & Frontline worker performance & advice_age_bf & $0-2$ \\
\hline 44 & Immediate breastfeeding & Nutrition & Mother's behaviour & r_bfl & $0-2$ \\
\hline 45 & Exclusive breastfeeding in the past 24 hours & Nutrition & Mother's behaviour & EBF_last24hrs & $0-2$ \\
\hline
\end{tabular}


Table 2. Continued

\begin{tabular}{|c|c|c|c|c|c|}
\hline & InDicAToR & $\begin{array}{l}\text { ContinuUm OF CARE } \\
\text { DOMAIN }\end{array}$ & Delivery PLATFORM & VARIABLE NAME & $\begin{array}{l}\text { AGE } \\
\text { GROUP }\end{array}$ \\
\hline 46 & Initiation of complementary feeding & Nutrition & Mother's behaviour & initiate_CF & $9-11$ \\
\hline 47 & $\begin{array}{l}\text { Age-appropriate initiation of complementary feeding (6-8 } \\
\text { months of age) }\end{array}$ & Nutrition & Mother's behaviour & age_initiate_cf & $9-11$ \\
\hline 48 & $\begin{array}{l}\text { Age-appropriate frequency of complementary feeding ( } 3+ \\
\text { times for 9-11 months-old children) }\end{array}$ & Nutrition & Mother's behaviour & age_approp_freq_cf & $9-11$ \\
\hline 49 & Fed complementary cereal-based food in past 24 hours & Nutrition & Mother's behaviour & Cereal & $9-11$ \\
\hline 50 & FLW reminded on vaccine information & Immunisation & Frontline worker performance & & $0-2$ \\
\hline 51 & Have immunisation card & Immunisation & Facility/outreach service delivery & have_immcard & $9-11$ \\
\hline 52 & Polio (OPV3 or IPV) by card & Immunisation & Facility/outreach service delivery & polio3_card & $9-11$ \\
\hline 53 & DPT3 by card & Immunisation & Facility/outreach service delivery & dpt3_card & $9-11$ \\
\hline 54 & FLW asked interest in having more children & Family planning & Frontline worker performance & advice_askfp & $0-2$ \\
\hline 55 & FLW asked risk of becoming pregnant post-delivery & Family planning & Frontline worker performance & advice_pregrisk & $0-2$ \\
\hline 56 & FLW advised on sterilization post-delivery & Family planning & Frontline worker performance & advice_pptl & $0-2$ \\
\hline 57 & FLW advised on use of PPIUD post-delivery & Family planning & Frontline worker performance & advice_pptiud & $0-2$ \\
\hline 58 & Modern method of contraception used & Family planning & Mother's behaviour & use_modernfp & $9-11$ \\
\hline 59 & Washed hands before feeding child & Sanitation & Mother's behaviour & Washafterfeed & $9-11$ \\
\hline 60 & Washed hands after using toilet & Sanitation & Mother's behaviour & Washaftertoil & $9-11$ \\
\hline 61 & Used soap or detergent when washing hands before feed & Sanitation & Mother's behaviour & WAFuns & 9-11 \\
\hline 62 & Used soap or detergent when washing hands after toilet & Sanitation & Mother's behaviour & WATuns & $9-11$ \\
\hline
\end{tabular}

ANC - antenatal care, CHS - Community-based Household Survey, DPT - diphtheria-pertussis-tetanus, FLW - frontline worker, IFA - iron-folic acid, IPV - inactivated polio vaccine, OPV - oral polio vaccine, PPIUD - postpartum intrauterine device, SHG - self-help group

Prior to analysis, indicators were grouped into the following domains according to the continuum of care, as described previously [28]: antenatal care and birth preparedness, delivery (childbirth care), postnatal care, nutrition/complementary feeding, immunisation, family planning and sanitation. For each continuum-of-care domain, we further classified the indicators into one of three delivery platforms: FLW performance or behaviour, mother's behaviour, and facility care or outreach service delivery, as described previously [32].

\section{Statistical analysis}

We examined demographic characteristics for SHG-member and non-member women in Parivartan blocks $(n=64)$, JEEViKA+HL blocks $(n=37)$ and JEEViKA blocks $(n=433)$, separately. Then, we examined relevant comparisons by calculating odds ratios (ORs) and 95\% confidence intervals (CIs) for all 62 indicators using survey logistic regression.

To understand SHG health layering effects according to the timeline of program interventions, we calculated one set of ORs for CHS round 6 (mid 2014) separately, as this timing was related to the Parivartan NGO-led health layering intervention in 64 blocks. To further understand the transition to scale up of government-led health-layered JEEViKA+HL SHGs, we calculated a second set of ORs for CHS rounds 8 and 9 (2016-2017) in 37 blocks. Lastly, to isolate the effects of health layering, we compared SHG members in Parivartan and JEEViKA+HL blocks (101 blocks with NGO-led and government-led health-layered SHGs, combined) compared to SHG members in non-health-layered JEEViKA blocks (433 blocks). In each of the abovementioned analyses, we calculated separate survey logistic regression models, deriving ORs and 95\% CIs of the SHG term for each RMNCHN and sanitation indicator. Due to the large number of comparisons, we applied the False Discovery Rate (FDR) multiple comparison adjustment controlling procedure by Benjamini and Hochberg [35], applying an upward adjustment to the P values to control family-wise type I error, alpha, at 0.05 . We additionally adjusted all models for maternal age and focal child gender. For all models, a sensitivity adjustment for additional co-variates was performed, including household size, number of children, asset index, Hindu religion, Scheduled Tribe/Scheduled Caste, literacy level, whether the family lived with nuclear or extended family members, mother's and father's educational levels and whether the family lived in a Pucca (ie, solid, permanent, built of substantial material such as stone, brick, cement, concrete, or timber) house. As some of these adjustment variables were highly collinear with the primary predictor, SHG membership, and thus some models would not parameterise, we present data based on adjustment for maternal age and focal child gender only for our primary analyses. Analyses were reported in the form of forest plots according to RMNCHN and sanitation continuum-of-care domains. 


\section{Ethical considerations}

Permission for access and terms of CHS data use were agreed upon with CARE India through a data sharing agreement and approved by the Stanford University Institutional Review Board protocol \#39719. This study is part of the BMGF Bihar program which was registered with ClinicalTrials.gov number NCT02726230.

\section{Role of the funding source}

This study was supported by grants from the BMGF, including: OPP1 163688 to Stanford University for analyses and manuscript preparation, OPP1033907 to PCI for SHG health layering, OPP1141832 to Population Council for SHG evaluation, and OPP1084426 to CARE India for CHS evaluations. BMGF India Country Office program officers reviewed the manuscript for accuracy and adequate description of the interventions, study design, and data collection. The senior author had full access to the data and independence from the funders in the reporting of results, the interpretation of the data and the decision to publish the manuscript.

\section{RESULTS}

\section{Study population}

Socioeconomic and demographic characteristics of the study population are displayed in Table 3 and Table 4. Overall, compared to non-members, SHG members combined across the three SHG types (Parivartan, JEEViKA+HL, JEEViKA) across rounds 6-9 of CHS during 2014-2017 were slightly older, had more children, were more often from a Scheduled Caste and Hindu, less likely to have formal education/ literacy, and had poorer living conditions (ie, less likely to dwell in a 'pucca' house) and a lower average number of household assets. Thus, SHG member women were, in general, at greater social disadvantage or more marginalised than non-SHG members. This was by design, as Parivartan and JEEViKA targeted the formation of SHGs among the most marginalised women.

Table 3. Demographic characteristics of self-help group (SHG) members across various block groups, Community-based Household Surveys rounds 6-9 combined

\begin{tabular}{|c|c|c|c|c|c|c|c|c|c|c|c|c|c|c|c|c|c|c|}
\hline \multirow[b]{2}{*}{ Variable } & \multicolumn{3}{|c|}{$\begin{array}{l}\text { SHG MEMBERS IN } 37 \\
\text { JEEVKL + HL BLOCKS }\end{array}$} & \multicolumn{3}{|c|}{$\begin{array}{l}\text { SHG MEMBERS IN } 433 \\
\text { JEEVKKA BLOCKS }\end{array}$} & \multicolumn{3}{|c|}{$\begin{array}{l}\text { SHG MeMBeris IN } 64 \\
\text { PARIVARTAN Blocks }\end{array}$} & \multicolumn{3}{|c|}{$\begin{array}{l}\text { NON-SHG MEMBERS IN } \\
37 \text { BLOCKS }\end{array}$} & \multicolumn{3}{|c|}{$\begin{array}{l}\text { NON-SHG MEMBERS IN } \\
433 \text { JEEV/KA BLOCKS }\end{array}$} & \multicolumn{3}{|c|}{$\begin{array}{c}\text { Non-SHG MEMBer IN } 64 \\
\text { Parivartan blocks }\end{array}$} \\
\hline & $\mathrm{N}$ & Median & IQR & $\mathrm{N}$ & Median & IQR & $\mathrm{N}$ & Median & $\mathrm{IQR}$ & $\mathrm{N}$ & Median & IQR & $\mathrm{N}$ & Median & IQR & $\mathrm{N}$ & Median & IQR \\
\hline Age of mother & 840 & $24.4^{*}$ & $21.7-27.3$ & 7718 & $24.4^{*}$ & $\begin{array}{l}21.6- \\
27.5\end{array}$ & 1377 & $24.5^{*}$ & $21.6-27.6$ & 3298 & 22.4 & $\begin{array}{l}19.9- \\
24.9\end{array}$ & 43788 & 23.0 & $\begin{array}{l}20.4- \\
25.6\end{array}$ & 5669 & 22.7 & $\begin{array}{l}20.1- \\
25.3\end{array}$ \\
\hline Household size & 840 & $5.9^{*}$ & $4.6-8.2$ & 7718 & $6.0^{*}$ & $4.5-8.1$ & 1377 & $5.9 *$ & $4.6-7.8$ & 3298 & 6.6 & $4.7-9.1$ & 43788 & 6.6 & $4.7-9.0$ & 5669 & 6.6 & $4.7-9.0$ \\
\hline $\begin{array}{l}\text { Number of children in } \\
\text { household }\end{array}$ & 840 & $2.5^{*}$ & $1.5-3.6$ & 7718 & $2.6^{*}$ & $1.6-3.7$ & 1377 & $2.7^{*}$ & $1.6-3.9$ & 3298 & 1.6 & $1.0-2.7$ & 43788 & 1.7 & $1.0-2.9$ & 5669 & 1.7 & $1.0-2.9$ \\
\hline $\begin{array}{l}\text { Number of adults in } \\
\text { household }\end{array}$ & 840 & $2.1^{*}$ & $1.3-5.3$ & 7718 & $2.0^{*}$ & $1.3-5.0$ & 1377 & $1.9^{*}$ & $1.3-4.5$ & 3298 & 4.0 & $1.7-7.0$ & 43788 & 3.9 & $1.6-6.9$ & 5669 & 4.0 & $1.7-6.9$ \\
\hline Mother years of education & 840 & 0 & $0-5.6$ & 7718 & 0 & $0-6.0$ & 1377 & 0 & $0-4.3$ & 3298 & 1.5 & $0-8.5$ & 43788 & 0 & $0-8.3$ & 5669 & 0 & $0-7.6$ \\
\hline Father years of education & 806 & $4.0^{*}$ & $0-8.1$ & 7443 & $2.3^{*}$ & $0-7.9$ & 1323 & $0^{*}$ & $0-7.3$ & 3177 & 5.3 & $0-9.4$ & 42306 & 5.6 & $0-9.3$ & 5478 & 4.7 & $0-9.0$ \\
\hline
\end{tabular}

$\mathrm{HL}$ - health layering, $\mathrm{N}$ - sample size, IQR - interquartile range

* Significant difference between SHG members and and non-SHG members in the indicated block group, $\mathrm{P}<0.01$.

\section{Effects of Parivartan health-layered SHGs}

Nearly two thirds (64\%) of RMNCHN indicators which had been targeted through modules for health layering were significantly higher for SHG members compared to non-members in the 64 Parivartan blocks in 2014 (CHS round 6) (Figure 3; Table Sla in the Online Supplementary Document). Several key indicators were higher for Parivartan SHG members compared to non-members, including 2-fold higher pregnancy registration in the first trimester $(\mathrm{OR}=2.02,95 \% \mathrm{CI}=1.48-2.75)$, 3-fold higher skin-to-skin care $(\mathrm{OR}=3.23,95 \% \mathrm{CI}=2.3-4.5)$, and nearly 3 -fold higher dry cord care $(\mathrm{OR}=2.82,95 \% \mathrm{CI}=2.03$ 3.9) and immediate breastfeeding $(\mathrm{OR}=2.7,95 \% \mathrm{CI}=1.9-3.9)$. Sanitation indicators were unstable in round 6 and were not reported. Nearly all (96\%) FLW performance indicators had higher levels for SHG members than non-members in Parivartan blocks, nearly half (44\%) of mother's behaviour indicators had higher levels, and only one out of seven (14.2\%) of the facility/outreach service delivery variables receiving at least $90 \mathrm{IFA}$ tablets during pregnancy $(\mathrm{OR}=1.7, \quad 95 \% \mathrm{CI}=1.2-2.5)$ - had higher odds for SHG members in Parivartan blocks. 


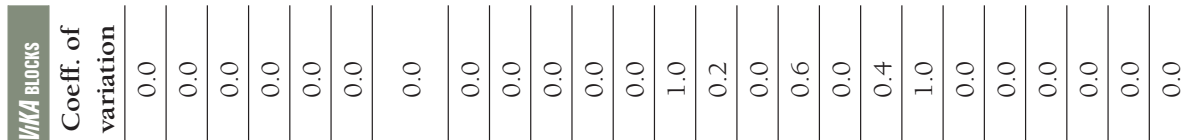

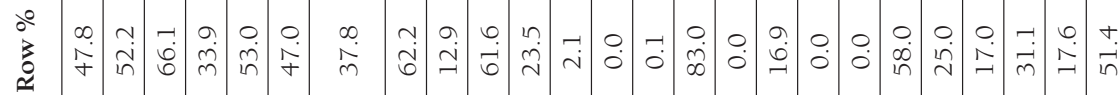

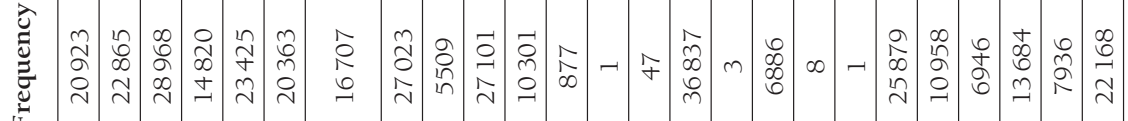

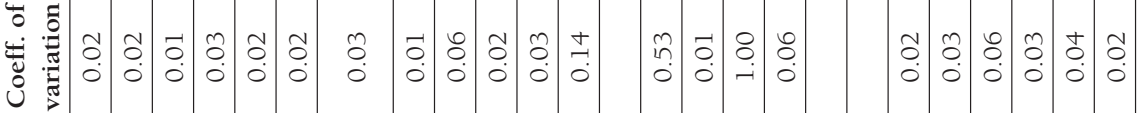

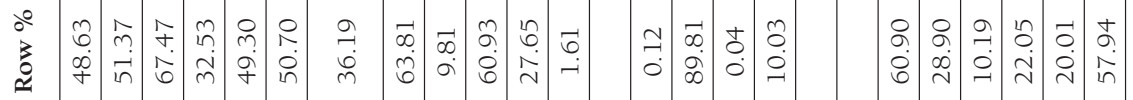

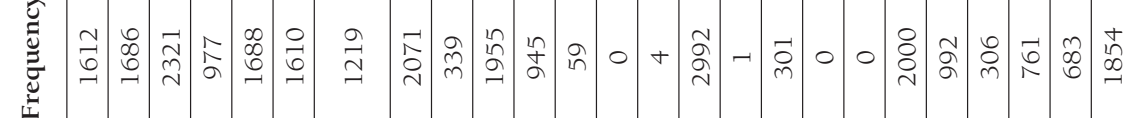

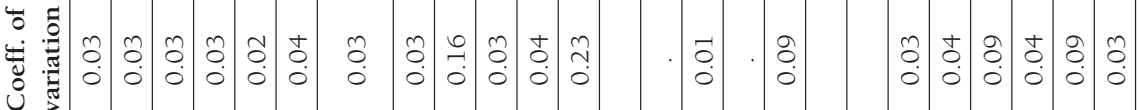

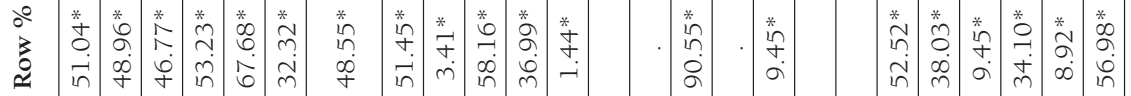

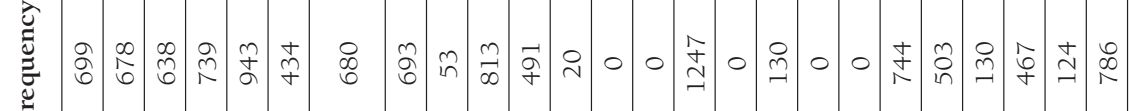

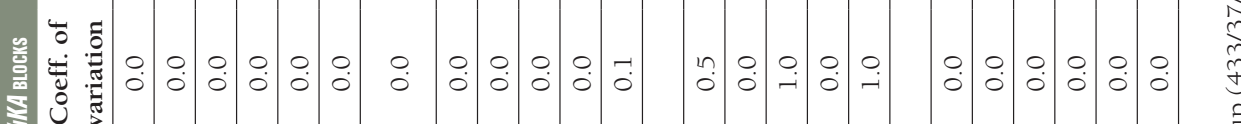

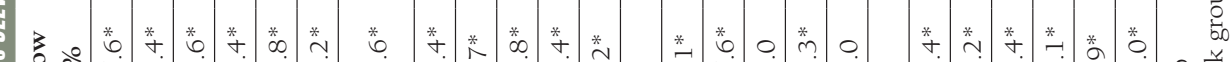

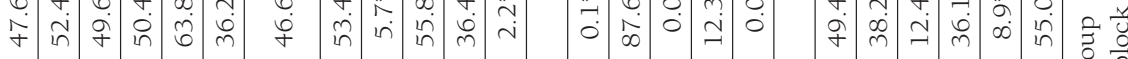

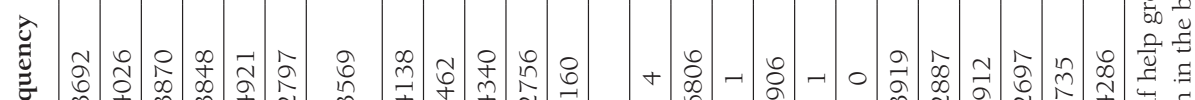

焉

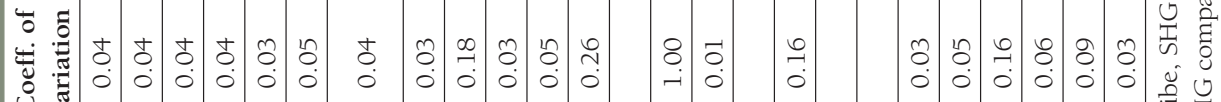

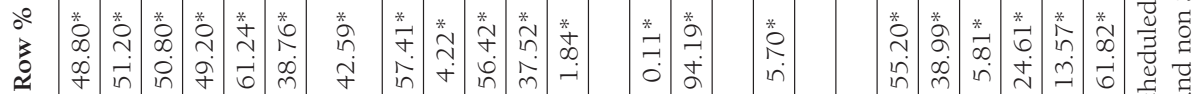

(1)

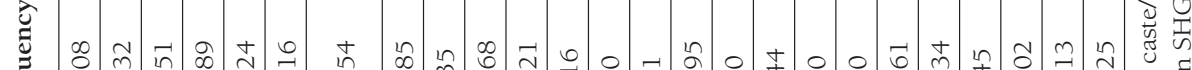

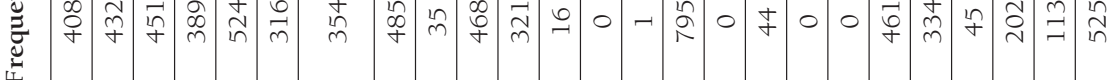

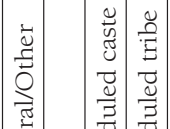

窎

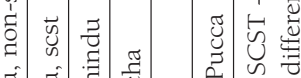

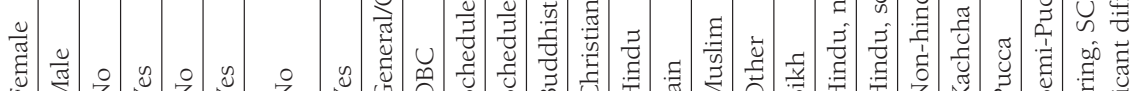

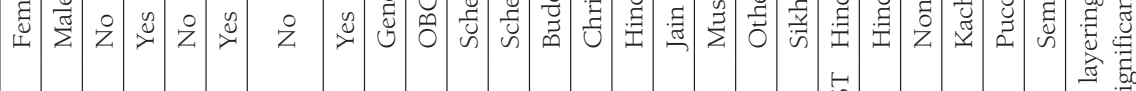




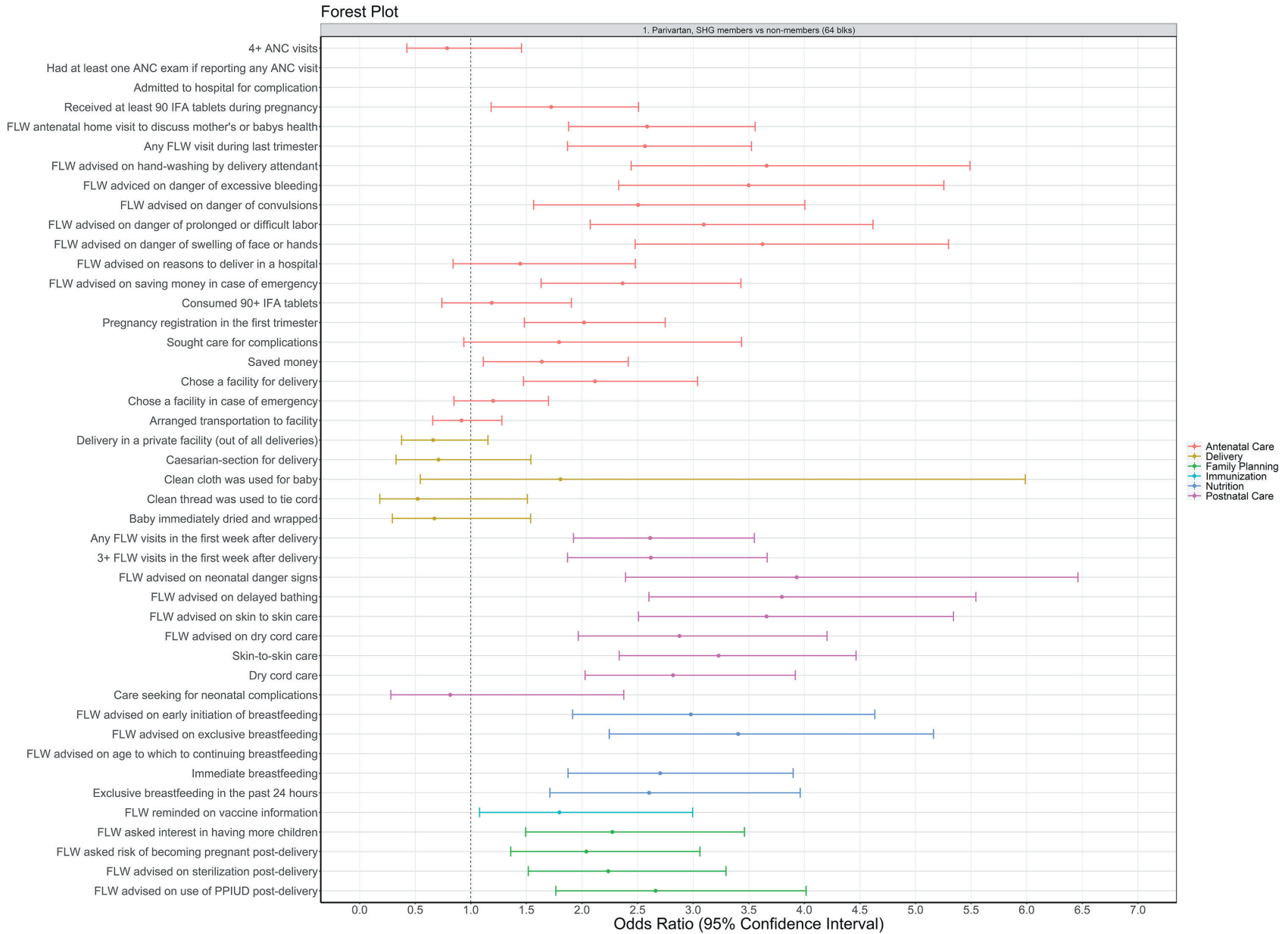

Figure 3. Effect of Parivartan health layering on reproductive, maternal, newborn and child health and nutrition indicators by continuum of care, CHS round 6 (2014), compared to non-members, 64 blocks (odds ratio, OR $\pm 95 \%$ confidence interval, CI). All models presented were adjusted for age of the mother and the sex of the focal child. These models also accounted for the study's complex design by applying study weights. ANC - antenatal care, CHS - Community-based Household Survey, DPT - diphtheria-pertussis-tetanus, FLW - frontline worker, HL - health layering, IFA - iron-folic acid, IPV - inactivated polio vaccine, OPV - oral polio vaccine, PPIUD - postpartum intrauterine device, SHG - self-help group (sanitation indicators were not included herein as the models did not parameterise).

\section{Effects of JEEViKA+HL health-layered SHGs}

In the $37 \mathrm{JEEViKA}+\mathrm{HL}$ blocks, over one quarter (27\%) of indicators had positive ORs for SHG members compared to non-members in rounds 8-9 (Figure 4, center; Table S1b in the Online Supplementary Document). One quarter (25\%) of antenatal, $22 \%$ of postnatal, $40 \%$ of nutrition, and $75 \%$ of family planning indicators were significantly higher for SHG members compared to non-members. Delivery, immunisation and sanitation indicators were similar for SHG members and non-members. Less than 5\% of indicators were worse for SHG members. In terms of delivery platform, 32\% of FLW performance indicators, $33 \%$ of mother's behaviour indicators, and $0 \%$ of the facility/outreach service delivery indicators had higher odds for SHG members than non-members in the 37 JEEViKA+HL blocks.

\section{Effects of non-health-layered JEEViKA SHGS}

In the 433 non-health-layered JEEViKA blocks, 50\% of RMNCHN indicators were significantly higher for SHG members compared to non-members in rounds 8-9 (Figure 4, right; Table S1c in the Online Supplementary Document). Across the continuum of care, $60 \%$ of antenatal, $44 \%$ of postnatal, $75 \%$ of nutrition, and all family planning indicators were higher for SHG members. Immunisation, delivery and sanitation indicators were similar for SHG members and non members. Overall, $12.5 \%$ of indicators were worse for SHG members in JEEViKA blocks. 


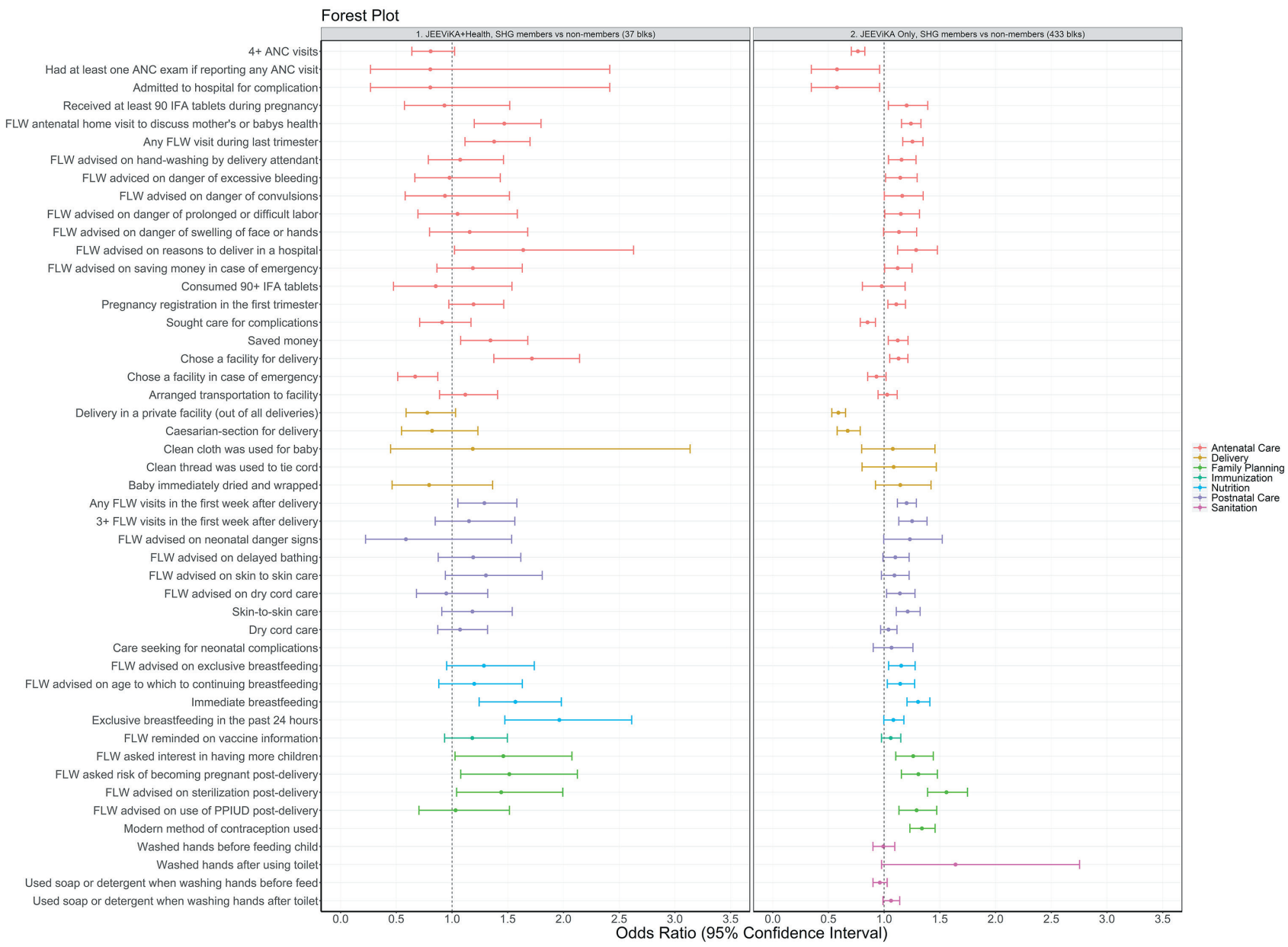

Figure 4. Effect of SHG interventions on reproductive, maternal, newborn and child health, nutrition and sanitation indicators by continuum of care, CHS rounds 8-9 (2016-2017), comparing health-layered JEEViKA+HL SHG members vs non-members, 37 blocks (odds ratio, $\mathrm{OR} \pm 95 \%$ confidence interval, $\mathrm{CI}$ ) (left) and non-health-layered JEEViKA SHG members vs non-members, 433 blocks $(\mathrm{OR} \pm 95 \% \mathrm{CI})$ (right). All models presented were adjusted for age of the mother and the sex of the focal child. These models also accounted for the study's complex design by applying study weights. ANC - antenatal care, CHS - Community-based Household Survey, DPT - pertussis-tetanus, FLW - frontline worker, HL - health layering, IFA - iron-folic acid, IPV - inactivated polio vaccine, OPV - oral polio vaccine, PPIUD - postpartum intrauterine device, SHG - self-help group.

\section{JEEViKA+HL compared to JEEViKA SHGs}

When comparing the performance of SHG members in the 101 blocks with health layering (64 Parivartan and 37 JEEViKA+HL blocks) to the performance of SHG members in 433 non-health-layered JEEViKA blocks in CHS rounds 8-9 from 2016-2017, half of indicators (50\%) had significantly higher odds in the health layered JEEViKA+HL groups compared to non-health-layered JEEViKA groups (Figure 5, Table S2 in the Online Supplementary Document). Health-layered SHG members showed significantly higher odds for half (50\%) of antenatal care, one fourth (22\%) of delivery, a majority (88\%) of postnatal, 55\% of nutrition, 33\% of family planning and no sanitation indicators. According to delivery platform, 70\% of FLW performance indicators, $41 \%$ of maternal behaviour indicators, and 17\% of facility/outreach service delivery indicators had significantly higher odds for SHG members with health layering compared to SHG members without health layering.

\section{DISCUSSION}

SHGs are a powerful vehicle for health promotion for women and young children. Our study utilised repeated, cross-sectional data to demonstrate improvements across a range of RMNCHN behaviours among members of health-layered SHGs. Our original hypothesis, that health-layered SHGs would out- 


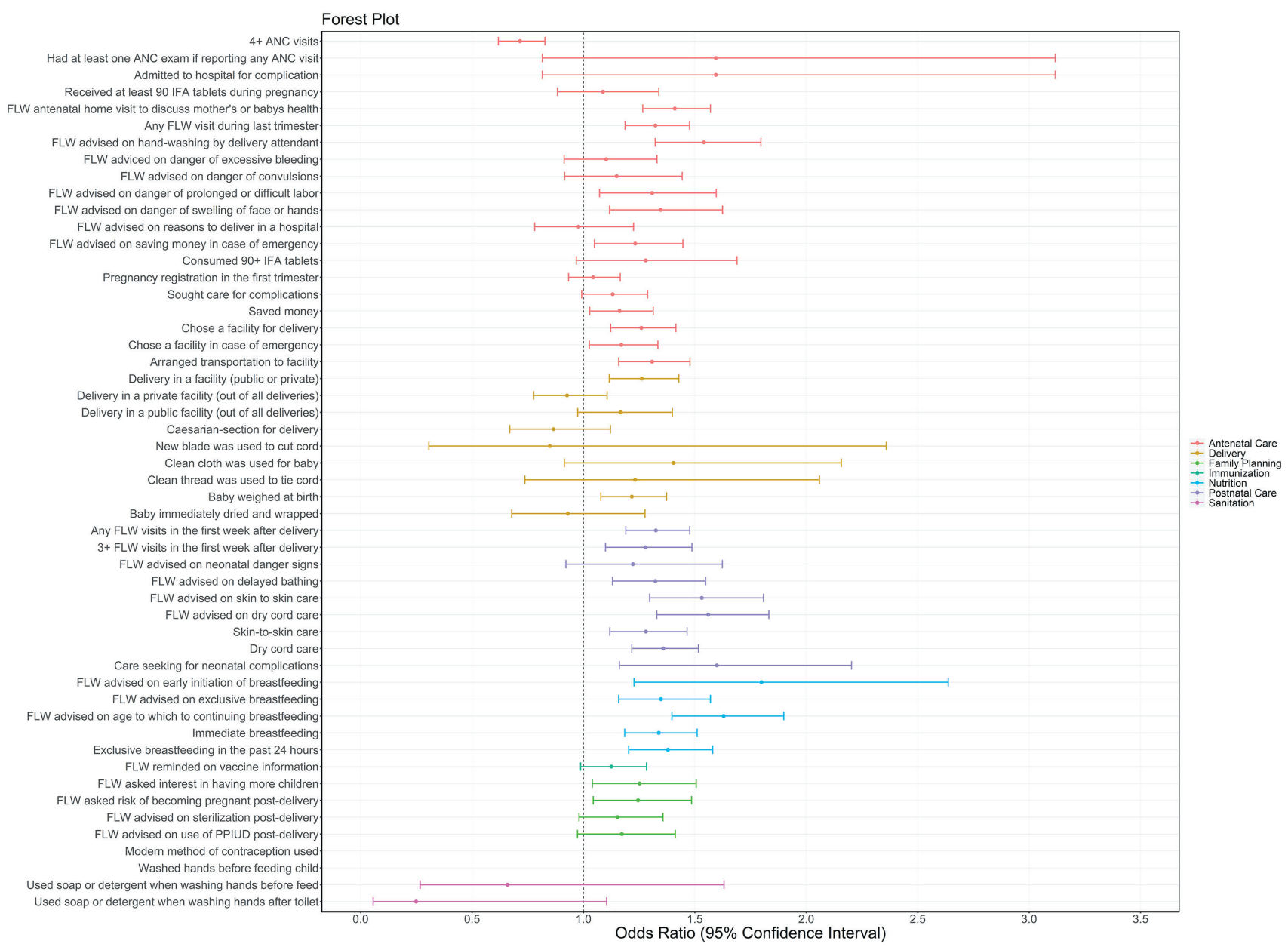

Figure 5. Effect of SHG interventions on reproductive, maternal, newborn and child health, nutrition and sanitation indicators by continuum of care, comparing members in health-layered SHGs (JEEViKA+HL and Parivartan) to members in non-health-layared JEEViKA SHGs, CHS rounds 8-9, 2016-2017. All models presented were adjusted for age of the mother and the sex of the focal child. These models also accounted for the study's complex design by applying study weights. ANC - antenatal care, CHS - Community-based Household Survey, DPT - diphtheria-pertussis-tetanus, FLW - frontline worker, HL - health layering, IFA - iron-folic acid, IPV - inactivated polio vaccine, OPV - oral polio vaccine, PPIUD - postpartum intrauterine device, SHG - self-help group.

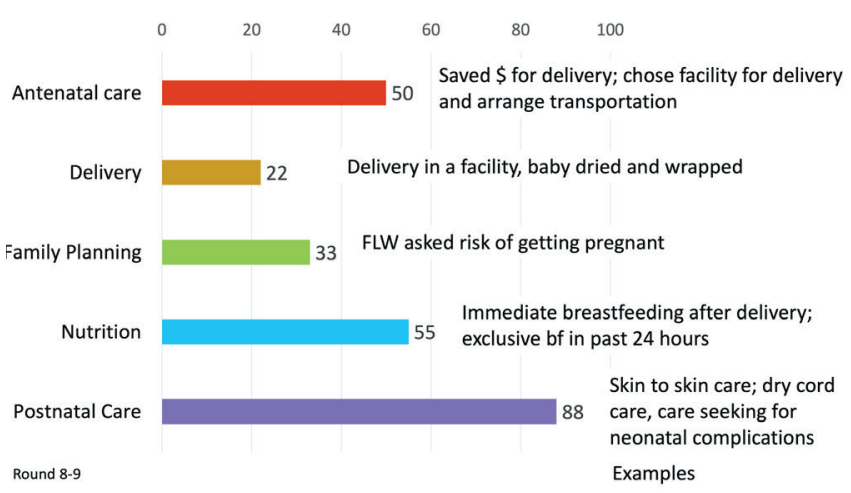

Figure 6. Summary of SHG interventions on reproductive, maternal, newborn and child health and nutrition domains, comparing members in health-layered SHGs (JEEViKA+HL and Parivartan) to members in non-health-layared JEEViKA SHGs, CHS rounds 8-9, 2016-2017. (\% of indicators where HL outperformed SHG alone). Sanitation indicators are not included here as sanitation indicators had similar effects in JEEViKA+HL and JEEViKA groups. perform non-health-layered SHGs held true, particularly for antenatal and postnatal care and nutrition, and less so for family planning, delivery care or sanitation (Figure 6). This expands the evidence for impact of microcredit and livelihood-focused SHGs, which have been studied in randomised controlled trials, [36] quasi-experimental $[37,38]$ and observational studies $[39,40]$, and have shown variable impacts on health. With focused health promotion within these SHGs, significant improvements in RMNCHN behaviours can be achieved.

This study demonstrated broad health impacts of NGOled health layering of SHGs, as well as the feasibility of adapting and transitioning health layering from an NGOled to a government-led model. The model for health layering was developed by the NGO, PCI, implemented at substantial scale in 64 blocks of Bihar, and showed significantly higher levels of approximately two-thirds of RMNCHN indicators in SHG members compared to non-members. Given the success with health layering, 
the JTSP was formed with PCI leadership to provide technical support to the government to layer health promotion onto government-led JEEViKA SHGs across 37 blocks with more modest impact, ie, approximately one-quarter of RMNCHN indicators were significantly higher among women members of JEEViKA+HL SHGs compared to non-members. Effects were most evident across the domains of antenatal care, birth preparedness, postnatal care and family planning, but were weaker for delivery care, complementary feeding/nutrition, sanitation and immunisation indicators. These results demonstrated the feasibility of transferring an NGO-developed model for health promotion to government-led SHGs at scale, although the findings also reveal the potential to further improve the health impact of government-led health-layered SHGs.

Finally, we showed that health layering of government-led SHGs (JEEViKA+HL) produced additional health benefits, particularly for antenatal care, postnatal care, nutrition and family planning beyond that seen for JEEViKA SHGs formed primarily for access to credit and livelihood promotion. Overall, $50 \%$ of indicators measured performed better in SHG members in 101 blocks with health-layered JEEViKA+HL SHGs compared to JEEViKA SHGs without health layering, despite the fact that non-health-layered SHGs had substantial impacts in improving health, as demonstrated previously [30]. Literature examining health-layered compared to non-health-layered SHGs is weak; despite a plethora of reviews, the quality of evidence appears to be low $[16,17]$, although some members of our team are now conducting a systematic review to comprehensively assess the evidence for SHG health layering. A new trial on the effects of participatory learning and action meetings layered upon SHGs is currently under way to examine nutritional outcomes, including complementary feeding, and dietary diversity and composition [41].

A novel finding in our study is that health layering was accomplished effectively at scale through government-led groups. Moreover, we documented effect sizes of government-led health-layered SHGs at scale of about the same magnitude as seen in prior reports of smaller-scale NGO-led pilot studies $[9,20]$, suggesting that governmental scale-up of health-layered SHGs under technomanagerial support of the JTSP was effective in promoting health improvements. While some Ananya-based interventions saw significant changes, the majority of non-SHG Ananya interventions showed more leveling of RMNCHN indicators during scale-up under the Bihar Technical Support Program, a similar support structure for non-SHG RMNCHN interventions [22,28]. In sharp contrast, SHG health layering had positive health benefit through the scale-up phase. The reasons for these positive effects may be that this government-led program operates through largely automous structures and functions - including human resources and performance management, largely funded by World Bank loans - and with strong political support and JEEViKA program leadership. This has ensured steady access to resources and committed and capable program staff at all levels.

Our findings also suggest that fertile ground exists in Bihar for further health-layering of SHGs statewide, which may have an added impact on health equity. Our previous work suggests large variation in equity, and health promotion upon SHGs may be a way to address these large differences [42]. SHG members in non-health-layered JEEViKA blocks performed better in half of RMNCHN indicators than age-comparable non-SHG-members residing in the same blocks, demonstrating substantial benefits of group membership and the potential for further health layering. For all three types of SHGs (Parivartan, JEEViKA+HL, JEEViKA), improvements in RMNCHN indicators were seen compared to women who were not in groups [30], in spite of the observation that women in groups were more highly marginalised than non-group members. Given that the women targeted by SHGs are more marginalised - on average having more children, less education, and greater levels of poverty - the positive effects of health layering are even more remarkable.

The findings regarding the impacts of SHGs on specific domains of health largely corroborated earlier findings by Saggurti et al. $[9,20]$, showing similar increases in skin-to-skin care, timely initiation of breastfeeding, exclusive breastfeeding, and increased use of modern contraception/family planning. Less impacts were seen on facility-based deliveries, similar to our prior work for women in Bihar in general [27]. However, our study extends this prior research as we captured a full range of RMNCHN and sanitation indicators over the first one thousand days of a child's life. It may be that underpinning SHG effectiveness are innate human evolutionary bonding mechanisms, where women during/after pregnancy value the advice from older women, which they are likely to uptake. Drawing upon this, it is also conceivable that benefits of SHG participation extended even beyond the activities measured in this evaluation. Mutual synergies must be explored across sectors in future research. For example, layering health upon SHGs formed for women's economic empowerment may lead to increases in other person-centered care across health, nutrition, sanitation and hygiene, and in health education, for example HIV aware- 
ness. Beyond this, there may be impacts related to individual and collective agency and action related to outcomes beyond health, such as gender-based violence and other gender-related or social issues. Recent reviews corroborate these findings that SHG membership positively affects several health indicators and behaviours, including neonatal [5] and maternal mortality [15,43], through "planned, do, study act cycles" [15,41,44,45] and for HIV indicators [10] and mental health [12,15]. Moreover, prior research has indicated that SHGs, specifically those linked to microfinance, increase non-health outcomes like financial outcomes, links to community health access, and health care financing/insurance $[13,14,18,19]$. Other reviews on SHGs suggest that impacts can be seen in agricultural SHGs [10], and that effects seen in older women can also be seen in adolescents [11].

Compared to other studies of SHG membership, this evaluation had several strengths. It 1) included a comparison group of non-SHG members to establish the feasibility of scaling up health-layered SHGs; 2) determined and compared SHG effects on a variety of indicators, across the RMNCHN continuum of care from pregnancy to early childhood and through several delivery platforms; and 3) examined specific contributions of health layering compared to SHG groups without health layering, showing an additional positive effect of health layering on RMNCHN and sanitation outcomes.

In addition to successful scaling of the SHG platform with added health layering upon this platform, there may be cyclic gains when SHG women gain empowerment, which potentially also acts as a lever for improving health, for example through increasing demand for services or accessing and connecting with the subcentre platform. This cyclic action derives from the conceptual theories of change that underlie the SHG program model. SHGs encompass a participant empowerment model, wherein SHG members engage in group actions which increase self-efficacy and women's trust in the health system, and encourage women to have specific dialogues about their circumstances, thereby increasing the autonomy of women's health as well as their collective efficacy and utilisation of health services. Close access to primary health care has been linked to improved health outcomes such as lower childhood mortality, substantiating the importance of providing health services locally in a manner that is both acceptable and impacts women (Irani L, unpublished results).

Our evaluation had some limitations. First, this study did not utilise an experimental design and thus, confounders which were unaccounted for may have influenced the results. For example, we found differences between women in SHGs compared to women not in SHGs, with the former more marginalised. In addition, the uptake and adherence to the health layering component was not measured in this study, and should be documented in future work with SHGs. It may be that other factors that differentially influence more marginalised compared to less marginalised women, other than health promotion through SHGs, may have served to improve health indicators in women in SHGs. This requires evaluation in future studies. Future randomised, stepped-wedge or factorial designs could be used to examine health layering upon the government-led and scaled SHGs to further tease apart programmatic choices which would lead to greater efficiency of SHGs in promoting health, such as group size, facilitation including leader qualities, costs, and potential for sustainable impact [41]. We categorised SHG type according to the geolocation of the blocks, as we lacked data on whether groups belonged to a particular program (eg, Parivartan or JEEViKA). Further specification could elucidate whether groups for specific purposes such as agriculture or strictly microfinance were optimal for layering interventions. In addition, specific health layering modules could be developed and examined using randomisation in a stepped-wedge or adaptive trial design and measuring specific, program-targeted process measures, indicators and outcomes.

In summary, this study demonstrates the benefits of layering health interventions upon government-led SHGs at scale in Bihar, India. These results should be a call to action for the GoB and other state-led government agencies to capitalise on this platform for health change at scale. 


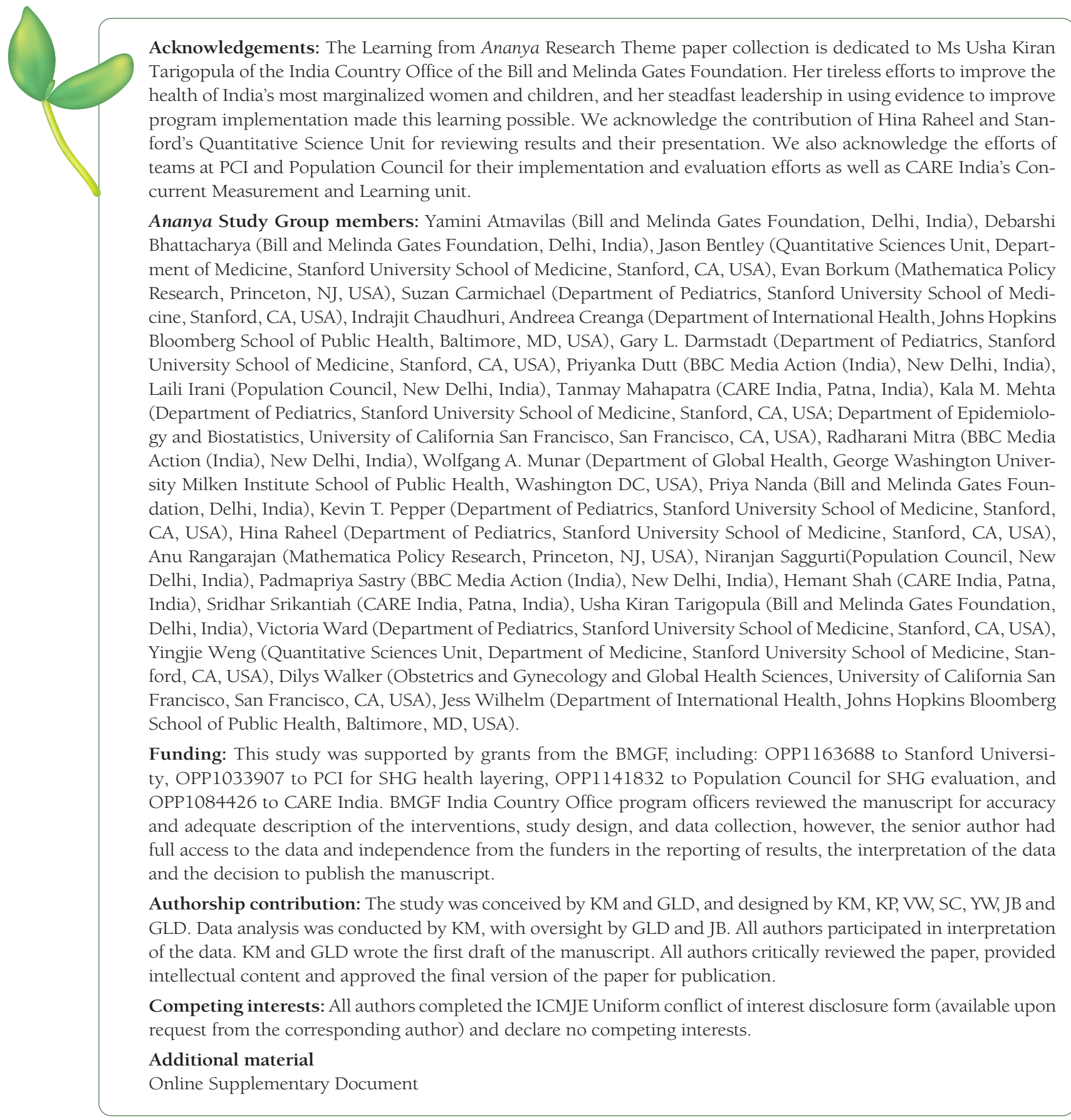

1 Transforming our World: The 2030 Agenda for Sustainable Development. Geneva, Switzerland: United Nations Development Program, 2015 Contract No.: A/RES/70/1.

2 Brody C, De Hoop T, Vojtkova M, Warnock R, Dunbar M, Murthy P, et al. Economic self-help group programmes for improving women's empowerment: a systematic review. London: International Initiative for Impact Evaluation (3ie); 2016.

3 Kumar N, Raghunathan K, Arrieta A, Jilani A, Chakrabarti S, Menon P, et al. Social networks, mobility, and political participation: The potential for women's self-help groups to improve access and use of public entitlement schemes in India. World Dev. 2019;114:28-41. Medline:31007353 doi:10.1016/j.worlddev.2018.09.023

4 Sen A. The Many Faces of Gender Inequality: The New Republic; 2001.

5 Houweling TA, Looman C, Azad K, Das S, King C, Kuddus A, et al. The equity impact of community women's groups to reduce neonatal mortality: a meta-analysis of four cluster randomized trials. Int J Epidemiol. 2019;48:168-82. Medline:29024995 doi:10.1093/ije/dyx160

6 Houweling TA, Tripathy P, Nair N, Rath S, Rath S, Gope R, et al. The equity impact of participatory women's groups to reduce neonatal mortality in India: secondary analysis of a cluster-randomised trial. Int J Epidemiol. 2013;42:520-32. Medline:23509239 doi:10.1093/ije/dyt012 
7 National Bank for Agriculture and Rural Development Act. Annual Report, 2017-2018. New Delhi, India: 2018.

8 World Bank. A decade of rural transformation: lessons learnt from the Bihar Rural Livelihoods Project - JEEViKA (English). Washington, D.C.: World Bank; 2018.

9 Saggurti N, Atmavilas Y, Porwal A, Schooley J, Das R, Kande N, et al. Effect of health intervention integration within women's self-help groups on collectivization and healthy practices around reproductive, maternal, neonatal and child health in rural India. PLoS One. 2018;13:e0202562. Medline:30138397 doi:10.1371/journal.pone.0202562

10 Gugerty MK, Biscaye P, Anderson C. Delivering development? Evidence on self-help groups as development intermediaries in South Asia and Africa. Dev Policy Rev. 2019;37:129-51. Medline:32494112 doi:10.1111/dpr.12381

11 Haberland NA, McCarthy KJ, Brady M. A Systematic Review of Adolescent Girl Program Implementation in Lowand Middle-Income Countries: Evidence Gaps and Insights. J Adolesc Health. 2018;63:18-31. Medline:29434004 doi:10.1016/j.jadohealth.2017.11.294

12 Madhani FI, Tompkins C, Jack SM, Fisher A. Participation in Micro-Finance Programmes and Women's Mental Health in South Asia: A Modified Systematic Review. J Dev Stud. 2015;51:1255-70. doi:10.1080/00220388.2015.1036037

13 Lorenzetti LMJ, Leatherman S, Flax VL. Evaluating the effect of integrated microfinance and health interventions: an updated review of the evidence. Health Policy Plan. 2017;32:732-56. Medline:28453714 doi:10.1093/heapol/czw170

14 Leatherman S, Metcalfe M, Geissler K, Dunford C. Integrating microfinance and health strategies: examining the evidence to inform policy and practice. Health Policy Plan. 2012;27:85-101. Medline:21343235 doi:10.1093/heapol/czr014

15 Orton L, Pennington A, Nayak S, Sowden A, White M, Whitehead M. Group-based microfinance for collective empowerment: a systematic review of health impacts. Bull World Health Organ. 2016;94:694-704A. Medline:27708475 doi:10.2471/BLT.15.168252

16 O'Malley TL, Burke JG. A systematic review of microfinance and women's health literature: Directions for future research. Glob Public Health. 2017;12:1433-60. Medline:27080539 doi:10.1080/17441692.2016.1170181

17 Irani L, Atmavilas Y, Hazra A, Verma S, Ahmad J, Das M, et al. Evaluating the integration of health and non-health programs into self-help groups in Bihar and Uttar Pradesh. New Delhi: Population Council, 2018.

18 Saha S, Annear PL, Pathak S. The effect of self-help groups on access to maternal health services: evidence from rural India. Int J Equity Health. 2013;12:36. Medline:23714337 doi:10.1186/1475-9276-12-36

19 Saha S, Kermode M, Annear P. Effect of combining a health program with a microfinance-based self-help group on health behaviors and outcomes. Public Health. 2015;129:1510-8. Medline:26304181 doi:10.1016/j.puhe.2015.07.010

20 Saggurti N, Porwal A, Atmavilas Y, Walia M, Das R, Irani L. Effect of behavioral change intervention around new-born care practices among most marginalized women in self-help groups in rural India: analyses of three cross-sectional surveys between 2013 and 2016. J Perinatol. 2019;39:990-9. Medline:30940930 doi:10.1038/s41372-019-0358-1

21 Darmstadt GL, Pepper KT, Ward VC, Srikantiah S, Mahapatra T, Tarigopula UK, et al. Improving primary health-care delivery in Bihar, India: Learning from piloting and statewide scale-up of Ananya. J Glob Health. 2020;10:021001. doi:10.7189/jogh.10.021001

22 Darmstadt GL, Weng Y, Pepper KT, Ward VC, Mehta KM, Borkum E, et al. Impact of the Ananya program on reproductive, maternal, newborn and child health and nutrition in Bihar, India: early resuults from a quasi-experimental study. J Glob Health. 2020;10:021002. doi:10.7189/jogh.10.021002

23 CARE India. Bihar Technical Support Unit. 2013.

24 CARE India. What change have we catalysed in Bihar so far? 2015

25 CARE India. Maternal and Neonatal Child Health - Bihar Story. 2018.

26 CARE India. The story of Bihar 2014-2015: Data-driven account of BTSP implementation efforts. 2016.

27 Creanga AA, Srikantiah S, Mahapatra T, Das A, Sonthalia S, Moharana PR, et al. Statewide implementation of a quality improvement initiative for reproductive, maternal, newborn, and child health and nutrition in Bihar, India. J Glob Health. 2020;10:021008. doi:10.7189/jogh.10.021008

28 Abdalla S, Weng Y, Mehta KM, Mahapatra T, Srikantiah S, Shah H, et al. Trends in reproductive, maternal, newborn and child health and nutrition indicators during five years of piloting and scaling-up of Ananya interventions in Bihar, India. J Glob Health. 2020;10:021003. doi:10.7189/jogh.10.021003

29 Ward VC, Raheel H, Weng Y, Mehta KM, Dutt P, Mitra R, et al. Impact of mHealth interventions for reproductive, maternal, newborn and child health and nutrition at scale: BBC Media Action and the Ananya program in Bihar, India. J Glob Health. 2020;10:021005. doi:10.7189/jogh.10.021005.

30 Mehta KM, Irani L, Chaudhuri I, Mahapatra T, Schooley J, Srikantiah S, et al. Health impact of self-help groups scaled up statewide in Bihar, India. J Glob Health. 2020;10:021006. doi:10.7189/jogh.10.021006

31 Population Council and Project Concern International. Evalutaion of the Community Mobilisation (Parivartan) Project Promoting Family Health Sanitation Behaviors in Bihar. New Delhi, India: 2013.

32 Mehrotra P, Saggurti N, Porwal A. Community mobilization project (Parivartan) for improving family health behaviors in Bihar: Midterm Evaluation. New Delhi, India: Population Council., 2015.

33 A Decade of Rural Transformation, lessons learnt from the Bihar Rural Livelihoods Project-JEEVIKA. Bihar, India: International Bank for Reconstruction and Development / The World Bank, 2017.

34 Robertson SE, Valadez J. Global review of health care surveys using lot quality assurance sampling (LQAS), 1984-2004. Soc Sci Med. 2006;63:1648-60. Medline:16764978 doi:10.1016/j.socscimed.2006.04.011

35 Benjamini Y, Hochberg Y. Controlling the False Discovery Rate: A Practical and Powerful Approach to Multiple Testing. J R Stat Soc B. 1995;57:289-300. doi:10.1111/j.2517-6161.1995.tb02031.x 
36 Miller LC, Joshi N, Lohani M, Rogers B, Loraditch M, Houser R, Singh P, et al. Community development and livestock promotion in rural Nepal: effects on child growth and health. Food Nutr Bull. 2014;35:312-26. Medline:25902591 doi: $10.1177 / 156482651403500304$

37 Prennushi G, Gupta, A. Women's empowerment and socio-economic outcomes: impacts of the Andhra Pradesh rural poverty reduction program. 2014.

38 Pitt MM, Khandker SR, Chowdhury OH, Millimet DL. Credit programs for the poor and the health status of children in rural Bangladesh. Int Econ Rev. 2003;44:87-118. doi:10.1111/1468-2354.t01-1-00063

39 Hallman KLD, Begum S, editors. Assessing the impact of vegetable and fishpond technologies on poverty in rural Bangladesh: Johns Hopkins University Press; 2007.

40 Habib MJC. Poverty alleviation with microfinance: Bangladesh evidence. policies reduct. Polic Pract Dev Asia. 2015:11-30

41 Kadiyala S, Prost A, Harris-Fry H, O’Hearn M, Pradhan R, Pradhan S, et al. Upscaling Participatory Action and Videos for Agriculture and Nutrition (UPAVAN) trial comparing three variants of a nutrition-sensitive agricultural extension intervention to improve maternal and child nutritional outcomes in rural Odisha, India: study protocol for a cluster randomised controlled trial. Trials. 2018;19:176. Medline:29523173 doi:10.1186/s13063-018-2521-y

42 Ward VC, Weng Y, Bentley J, Carmichael SL, Mehta KM, Mahmood W, et al. Evaluation of a large-scale reproductive, maternal, newborn and child health and nutrition program in Bihar, India through an equity lens. J Glob Health. 2020;10:021011. doi:10.7189/jogh.10.021011.

43 Prost A, Colbourn T, Seward N, Azad K, Coomarasamy A, Copas A, et al. Women's groups practising participatory learning and action to improve maternal and newborn health in low-resource settings: a systematic review and meta-analysis. Lancet. 2013;381:1736-46. Medline:23683640 doi:10.1016/S0140-6736(13)60685-6

44 Tripathy P, Nair N, Sinha R, Rath S, Gope RK, Rath S, et al. Effect of participatory women's groups facilitated by Accredited Social Health Activists on birth outcomes in rural eastern India: a cluster-randomised controlled trial. Lancet Glob Health. 2016;4:e119-28. Medline:26823213 doi:10.1016/S2214-109X(15)00287-9

45 Prost A, Colbourn T, Tripathy P, Osrin D, Costello A. Analyses confirm effect of women's groups on maternal and newborn deaths. Lancet. 2013;381:e15. Medline:23683648 doi:10.1016/S0140-6736(13)61082-X 